\title{
PROPRIEDADES FÍSICAS DA MADEIRA E DE PAINÉIS AGLOMERADOS PRODUZIDOS COM MISTURAS DE ESPÉCIES FLORESTAIS
}

\author{
Lygia Maria Napoli ${ }^{1}$, Felipe Luis Sanches ${ }^{2}$, Setsuo Iwakiri ${ }^{3}$, Éverton Hillig ${ }^{4}$ \\ ${ }^{1}$ Eng $^{a}$. Florestal, Irati, PR, Brasil - napoli @ florestal.eng.br \\ ${ }^{2}$ Eng. Florestal, Irati, PR, Brasil - engenhariaflorestal.felipe@gmail.com \\ ${ }^{3}$ Eng. Florestal, Dr., Depto. de Engenharia e Tecnologia Florestal, UFPR, Curitiba, PR, Brasil - setsuo@ufpr.br \\ ${ }^{4}$ Eng. Florestal, Dr., Depto. de Engenharia Florestal, UNICENTRO, Irati, PR, Brasil - hillig@ hotmail.com \\ Recebido para publicação: 26/03/2012 - Aceito para publicação: 02/07/2013
}

\begin{abstract}
Neste trabalho, foram avaliadas as propriedades físicas da madeira e de painéis aglomerados produzidos com Mimosa scabrella Bentham (bracatinga) e Hovenia dulcis Thunb (uva-do-japão), visando estabelecer parâmetros para sua utilização em misturas com madeira de Pinus taeda L. (pinus) e de Eucalyptus saligna Smith (eucalipto). Foram produzidos painéis de três camadas com misturas de partículas de madeira dessas espécies. Também foram produzidos painéis de três camadas e monocamada com madeira de pinus e partículas produzidas tanto em laboratório quanto em ambiente industrial. Avaliou-se a massa específica básica da madeira e as propriedades de estabilidade dimensional dos painéis. Confirmou-se que as madeiras de bracatinga e uva-do-japão são apropriadas para uso em misturas, devido sua maior massa específica. A análise dos painéis mostrou que a adição de madeira de eucalipto e de uva-do-japão reduz o inchamento em espessura. $\mathrm{Na}$ absorção d'água, essas madeiras também apresentaram comportamento positivo, no entanto a madeira de bracatinga contribuiu para maior absorção. Os painéis produzidos com 50\% de eucalipto e 50\% de uva-do-japão apresentaram melhor estabilidade dimensional, ao contrário dos painéis confeccionados com $50 \%$ de pinus e $50 \%$ de bracatinga. Os painéis produzidos com estrutura monocamada e com partículas de laboratório apresentaram tendência para menor inchamento em espessura. Entretanto, a mesma tendência não foi observada para absorção d'água.

Palavras-chave: Painéis de madeira; massa específica; Mimosa scabrella; Hovenia dulcis.
\end{abstract}

Resumo

\begin{abstract}
Physical properties of wood and particleboards produced with mixtures of forest species. This research evaluated the physical properties of wood and particle board produced with Mimosa scabrella Bentham and Hovenia dulcis Thunb, in order to establish parameters for its use in mixtures with wood of Pinus taeda L. and Eucalyptus salgina Smith. It was produced panels of three layers and monolayer with mixtures of these species of wood particles. It was also produced panels of three layers and monolayer with pine wood and particles produced as in laboratory as in industrial environments. We evaluated the basic specific mass of the wood properties, as the properties of dimensional stability of the panels. It was confirmed that the timber of Mimosa scabrella and Hovenia dulcis are suitable for use in mixtures, due to its greater density. The analysis of the panels revealed that addition of Eucalyptus saligna and Hovenia dulcis reduces the thickness swelling. In water absorption, these woods also showed positive behavior, but the Mimosa scabrella wood contributed to enhanced absorption. The panels produced with 50\% Eucalyptus saligna and 50\% Hovenia dulcis showed better dimensional stability, unlike panels made with 50\% Pinus taeda and 50\% Mimosa scabrella. The panels produced with homogeneous structure and laboratory particle showed inclination to have thickness lower swelling. However, the same trend was not observed for water absorption.

Keywords: Wood panels; density; Mimosa scabrella; Hovenia dulcis.
\end{abstract}

\section{INTRODUÇÃO}

A indústria de painéis aglomerados surgiu no início da década de 40, na Alemanha, com a finalidade de aproveitar os resíduos industriais e das serrarias, frente à dificuldade de obter madeiras de boa qualidade para produção de compensados, devido ao seu isolamento durante a $2^{\mathrm{a}}$ Guerra Mundial. 
Com o final da guerra, os Estados Unidos retomaram o processo de desenvolvimento dos painéis, aperfeiçoando os equipamentos, instalações industriais e os processos produtivos.

No Brasil, os painéis aglomerados foram produzidos pela primeira vez em 1966, pela empresa Placas do Paraná S.A., em Curitiba, PR. Esse material, nas últimas décadas, teve boa aceitação no mercado, acompanhando a tendência verificada no mundo.

De acordo com a produção em larga escala de painéis associada à grande procura desse material, para os próximos anos estão previstos novos investimentos, com valores aproximados de US\$ 1,2 bilhão na instalação de novas unidades industriais, que irão proporcionar um aumento da capacidade instalada em 2009, de 8,8 milhões de metros cúbicos, para aproximadamente 11 milhões de metros cúbicos anuais a partir de 2012. Esse mercado vem sofrendo mudanças, em função dos seguintes fatores: busca de alternativas à madeira serrada; modernização tecnológica do parque fabril, que proporcionou a oferta de novos produtos, como OSB (oriented strand board) e a melhoria da qualidade do aglomerado, com a consequente mudança de nome para MDP (medium density particleboard); redução dos juros e melhoria da renda, que deram forte impulso à construção civil e ao setor de móveis, ambos consumidores de painéis de madeira (ABIPA, 2010).

Os painéis aglomerados são fabricados com partículas de madeira aglutinadas com adesivos sintéticos, por meio da prensagem sob alta temperatura. A principal vantagem desse produto é a de substituir a escassa e encarecida madeira serrada em diferentes usos, como na fabricação de móveis, portas, pisos e rodapés. São também aplicados na construção civil, em painéis de parede e forros, entre outros usos.

Para a fabricação dos painéis, as matérias-primas utilizadas incluem madeiras de várias espécies e outros materiais lignocelulósicos, como, por exemplo, bagaço de cana, casca de arroz, palha de linho etc Porém, do ponto de vista comercial, a qualidade do produto final limita o campo de aplicação.

As espécies de coníferas são as mais empregadas na produção dos painéis, devido à baixa massa específica da madeira. Em menor escala, a madeira de folhosas de média massa específica pode ser utilizada em mistura com madeira de espécies de baixa massa específica (IWAKIRI, 2005).

Segundo Cabral et al. (2007), as madeiras com massa específica superior a $0,60 \mathrm{~g} / \mathrm{cm}^{3}$ normalmente não são aceitas para a fabricação de aglomerados, pois resultarão em painéis com massa específica superior àquelas aceitas pelo mercado consumidor. No entanto, as espécies de maior massa específica podem ser utilizadas em mistura com as de menor massa específica, podendo, dessa forma, viabilizar o aproveitamento daquelas espécies. Ainda em referência à espécie, as variações na massa específica da madeira podem influenciar as operações de processamento, como geração de partículas, secagem, consumo de resina e prensagem dos painéis (MALONEY, 1993).

Vários trabalhos já foram realizados para viabilizar a produção de painéis de partículas a partir de misturas de espécies, algumas com sucesso, como a mistura de eucalipto e embaúba, na proporção de $50 \%$ de cada espécie, realizada por Haselein et al. (1989), que produziu painéis com propriedades melhores do que com cada espécie utilizada individualmente.

Misturando Pinus elliottii, Eucalyptus grandis e Acacia mearnssii para confeccionar painéis aglomerados, Hillig et al. (2002) concluíram que a massa específica foi a propriedade que mais teve influência sobre o módulo de ruptura à flexão (MOR) e sobre o módulo de elasticidade à flexão (MOE). A taxa de compressão teve menor influência sobre essas propriedades, principalmente nos painéis com maior proporção de Acacia mearnsii.

Hiziroglu et al. (2005) produziram painéis aglomerados de Dendrocalamus asper misturado com diferentes proporções de Eucalyptus camaldulensis e palha de arroz. Pode-se verificar que a inclusão de bambu nos painéis melhorou as propriedades mecânicas de MOR e MOE, e também na ligação interna, principalmente nos painéis com palha de arroz.

Bianche et al. (2012) se utilizaram do gênero Sida spp. (vassoura) para produzir painéis aglomerados em associação com eucalipto (Eucalyptus urophylla) e paricá (Schizolobium amazonicum). Verificaram que a utilização de partículas de vassoura, em geral, não influenciou nas propriedades mecânicas dos painéis. Por outro lado, os painéis produzidos com partículas de vassoura absorveram mais água e tiveram maior inchamento em espessura.

A bracatinga (Mimosa scabrella Benth) e a uva-do-japão (Hovenia dulcis Thunberg) podem vir a ser utilizadas na produção de painéis, pois seu rápido crescimento e facilidade de propagação são características que podem favorecer seu plantio. A massa específica de suas madeiras, aproximadamente 
$0,67 \mathrm{~g} / \mathrm{cm}^{3}$ e 0,60 $\mathrm{g} / \mathrm{cm}^{3}$, respectivamente (LORENZI, 2002; CARVALHO, 1994), faz com que sua utilização em aglomerados seja mais adequada em mistura com espécies de menor densidade.

Assim, este estudo teve por objetivo avaliar a massa específica da madeira e as propriedades físicas de painéis aglomerados produzidos com madeira proveniente das espécies Mimosa scabrella e Hovenia dulcis, em associação com madeiras de Pinus taeda L. e Eucalyptus saligna Smith, procurando determinar o efeito da mistura sobre as propriedades dos painéis.

\section{MATERIAL E MÉTODOS}

\section{Obtenção e caracterização da matéria-prima}

Para a realização do estudo, foram retiradas sete árvores, sendo duas para as espécies Hovenia dulcis (uva-do-japão), Mimosa scabrella (bracatinga) e Pinus taeda (pinus), e uma de Eucalyptus saligna (eucalipto). A região de coleta das árvores se situa no município de Irati, PR, paralelo $25^{\circ} 27^{\prime} 56^{\prime \prime}$ de latitude sul com intersecção com o meridiano 50 $37^{\prime} 51^{\prime \prime}$ de longitude oeste. O clima da região é, segundo a classificação climática de Köppen, tipo $\mathrm{Cfb}$ (temperado). Apresenta verões amenos, invernos com ocorrências de geadas severas e frequentes, não apresentando estação seca. As médias mensais de precipitação pluviométrica e da umidade relativa do ar são $193,97 \mathrm{~mm}$ e $79,58 \%$, respectivamente. A altitude média é de 820 metros.

A árvore de eucalipto foi retirada de uma área experimental do Colégio Estadual Presidente Costa e Silva, plantada em espaçamento 3 x 2, dominada, e tinha 22 anos à época do corte. As árvores restantes foram obtidas no Campus de Irati da UNICENTRO. Os exemplares de pinus, de bracatinga e de uva-do-japão foram escolhidos de áreas naturais do campus, sendo sua idade estimada em aproximadamente 12 anos.

A análise de massa específica da madeira foi realizada em cada árvore, sendo retirados discos com cinco centímetros de espessura a 0,10 m, 1,30 m (DAP), 2,50 m, 3,70 m e 4,90 m, pois foi a altura máxima utilizada do fuste de cada árvore.

A massa específica básica dos corpos de prova foi determinada pelo método da balança hidrostática. Após, determinaram-se a massa específica média aritmética e ponderada de cada árvore. Para a estimativa da média ponderada de cada árvore, utilizou-se a metodologia sugerida por Vital (1984), adaptada. Para o cálculo, consideraram-se os volumes das toras e as respectivas massas específicas dos corpos de prova de cada disco. O cálculo foi realizado por meio da equação (1):

$$
M e_{m p}=\frac{M e_{0,10-1,30} * V_{0,10-1,30}+\ldots+M e_{3,70-4,90} * V_{3,70-4,90}}{V_{(0,10-1,30)}+V_{(1,30-2,50)}+V_{(2,50-3,70)}+V_{(3,70-4,90)}}
$$

Em que: $\quad \mathrm{Me}_{\mathrm{mp}}=$ massa específica média ponderada da árvore $\left(\mathrm{g} / \mathrm{cm}^{3}\right)$;

$\mathrm{Me}=$ massa específica média de cada disco $\left(\mathrm{g} / \mathrm{cm}^{3}\right) ; \mathrm{e}$

$\mathrm{V}=$ volume de cada tora entres os discos $\left(\mathrm{m}^{3}\right)-($ Fórmula de Smalian $)$.

\section{Confecção dos painéis aglomerados}

As árvores foram seccionadas em toras e posteriormente desdobradas numa serra fita em tábuas com espessura de $2,7 \mathrm{~cm}$. Numa plaina, foi possível gerar maravalhas, sendo estas então processadas em moinho de martelos, obtendo partículas tipo grânulos, com dimensões homogêneas. Após, as partículas de cada espécie obtidas de todas as toras foram homogeneizadas para posterior classificação.

As partículas foram classificadas numa classificadora de peneiras com base nas suas dimensões. As partículas que passaram pela peneira 14 (12 mesh), com abertura de 1,42 $\mathrm{mm}$, foram utilizadas nas superfícies dos painéis. Já as partículas que ficaram retidas pela peneira, consideradas grossas, foram utilizadas para o miolo dos painéis. Após a classificação, as partículas foram secas em estufa com ventilação de ar forçada, a $80{ }^{\circ} \mathrm{C}$, até teor de umidade médio de $3 \%$.

Foram produzidos painéis de três camadas, com misturas de madeiras e com partículas de pinus. Também foram produzidos painéis homogêneos de partículas de pinus (monocamada), utilizando-se somente partículas grossas, que ficaram retidas na peneira $12 \mathrm{mesh}$. Adicionalmente, foram produzidos 
painéis com partículas obtidas numa indústria de aglomerados localizada na região de Curitiba, PR. A produção dos painéis foi realizada no Laboratório de Painéis de Madeira do Departamento de Engenharia Florestal da UFPR, em Curitiba, PR. Para sua produção, levou-se em consideração a proporção de cada espécie na mistura e a densidade nominal do painel, fixada em $0,65 \mathrm{~g} / \mathrm{cm}^{3}$. Também foram controlados os parâmetros do processo produtivo, com uso de adesivo ureia-formaldeído com viscosidade de $650 \mathrm{cP}$, teor de sólidos de $68 \%$ e pH $=7,8$. A proporção de adesivo foi de $10 \%$ seco sobre peso seco de partículas nos painéis monocamada e no miolo dos painéis de três camadas. As camadas externas receberam $15 \%$ de adesivo. Utilizou-se também solução de parafina, com $30 \%$ de sólidos, na proporção de $1 \%$ seco sobre peso seco de partículas.

Às partículas das diferentes espécies de madeira foi aplicado adesivo, por meio de um misturador; posteriormente, elas foram levadas para pré-prensagem em prensa fria. Após, foram prensadas a quente, em prensa hidráulica, à temperatura de $160{ }^{\circ} \mathrm{C}$, pressão específica de $40 \mathrm{kgf} / \mathrm{cm}^{2}$ e tempo de prensagem de 10 minutos.

Foram produzidos 21 painéis aglomerados, com $50 \mathrm{~cm}$ de aresta e $1,2 \mathrm{~cm}$ de espessura, em diferentes proporções de misturas e em diferentes estruturas do colchão (painéis monocamada e painéis de três camadas). Os painéis foram acondicionados na sala de climatização, à temperatura de $20^{\circ} \mathrm{C}$ e $65 \%$ de umidade relativa, para posterior realização dos testes físicos.

\section{Avaliação das propriedades físicas}

Os testes realizados foram massa específica e estabilidade dimensional - absorção d'água e inchamento em espessura após 2 e 24 horas de imersão em água. Os ensaios foram realizados, segundo as recomendações da norma norte-americana ASTM/D1037-06 (ASTM, 2006), no Laboratório de Propriedades da Madeira da Universidade Estadual do Centro-Oeste, Campus Irati, PR.

Determinou-se a massa específica básica ao teor de umidade de equilíbrio (massa seca / volume ao teor de umidade de equilíbrio), utilizando os corpos de prova dos ensaios físicos.

\section{Análise dos resultados}

Foram avaliadas as propriedades de estabilidade dimensional após duas e 24 horas de imersão em água: absorção d'água em peso (AP2 a AP24), absorção d'água em volume (AV2 e AV24) e inchamento em espessura (IE2 e IE24), correlacionadas entre si e com a massa específica.

$\mathrm{O}$ experimento foi composto por sete tratamentos com três repetições, que variaram conforme a proporção de cada espécie na mistura, a estrutura do painel e a origem das partículas. A caracterização dos tratamentos pode ser visualizada na tabela 1 . Os painéis dos tratamentos 5 e 7 foram confeccionados utilizandose partículas geradas na indústria, e a estrutura dos painéis dos tratamentos 6 e 7 foi em monocamada.

Para a comparação entre os tratamentos, foi realizada análise de variância (ANOVA) e teste de médias (Tukey), para verificar a significância das diferenças entre as médias. Após, foi realizado o teste de Pearson, para verificar as correlações entre as variáveis. Nessa análise, foram considerados apenas os tratamentos que utilizaram partículas industriais, pois as variáveis de estabilidade dimensional foram correlacionadas com a proporção de cada espécie no painel.

Tabela 1. Caracterização dos tratamentos para confecção dos painéis.

Table 1. Treatments characterization for the panels manufacture.

\begin{tabular}{lcccccc}
\hline \multirow{2}{*}{ Tratamentos } & \multirow{2}{*}{ Camadas } & \multirow{2}{*}{ Partículas } & \multicolumn{4}{c}{ Proporção de cada espécie (\%) } \\
\cline { 4 - 6 } & 3 & Laboratório & 50 & - & 50 & - \\
\hline 1 & 3 & Laboratório & 50 & - & - & 50 \\
2 & 3 & Laboratório & - & 50 & 50 & - \\
3 & 3 & Laboratório & - & 50 & - & 50 \\
4 & 3 & Indústria* & 100 & - & - & - \\
5 & 1 & Laboratório & 100 & - & - & - \\
6 & 1 & Indústria* & 100 & - & - & - \\
7 & &
\end{tabular}

${ }^{1}$ Proporção com base no peso seco total das partículas; * Partículas provenientes de uma empresa da região de Curitiba. 


\section{RESULTADOS E DISCUSSÃO}

\section{Massa específica da madeira}

$\mathrm{Na}$ tabela 2 estão apresentados os valores obtidos para a massa específica básica média ponderada $\left(\mathrm{Me}_{\mathrm{mp}}\right)$ e para massa específica básica média aritmética $\left(\mathrm{Me}_{\mathrm{ma}}\right)$ de cada árvore cubada. Verifica-se que a média de massa específica ponderada obtida para o pinus está dentro da faixa citada por Maloney (1993), até $0,55 \mathrm{~g} / \mathrm{cm}^{3}$, para assegurar uma taxa de compressão acima de 1,1. Para o eucalipto, foi encontrado um valor acima do recomendado. As médias encontradas para bracatinga e uva-do-japão também estão acima do valor recomendado, indicando a necessidade de mistura dessas espécies com outras de menor massa específica.

Tabela 2. Valores médios de massa específica básica por árvore e por espécie utilizada no estudo, com seus respectivos DAP's e altura comercial.

Table 2. Average values density by tree and by species under study, with their DAP's and commercial height.

\begin{tabular}{lccccc}
\hline Árvore & Espécie & $\mathbf{M e}_{\mathbf{m a}}$ & $\mathbf{M e}_{\mathbf{m p}}$ & $\mathbf{D A P}(\mathbf{c m})$ & Altura comercial $(\mathbf{m}) *^{*}$ \\
\hline 1 & Bracatinga & 0,61 & 0,62 & 15,60 & 5,18 \\
2 & Bracatinga & 0,57 & 0,58 & 22,60 & 7,15 \\
3 & Pinus & 0,36 & 0,38 & 15,30 & 4,98 \\
4 & Pinus & 0,34 & 0,35 & 17,60 & 5,93 \\
5 & Uva-do-japão & 0,55 & 0,55 & 15,10 & 6,17 \\
6 & Uva-do-japão & 0,61 & 0,58 & 16,80 & 5,95 \\
7 & Eucalipto & 0,56 & 0,58 & 18,50 & 7,44 \\
\hline Média & & 0,52 & 0,52 & 17,36 & 6,11 \\
Desvio Padrão & 0,11 & 0,11 & 2,63 & 0,92 \\
Coeficiente de Variação & & 22,3 & 20,8 & 15,2 & 15,0 \\
\hline
\end{tabular}

$\mathrm{Me}_{\mathrm{ma}}$ : massa específica média aritmética; $\mathrm{Me}_{\mathrm{mp}}$ : massa específica média ponderada; *: altura comercial determinada pelo diâmetro mínimo de $7 \mathrm{~cm}$ ou por uma bifurcação.

Com exceção da uva-do-japão, para todas as demais espécies estudadas verificou-se que a $\mathrm{Me}_{\mathrm{mp}}$ foi maior que a $\mathrm{Me}_{\mathrm{ma}}$. Esse fato sugere que, se for usado a $\mathrm{Me}_{\mathrm{ma}}$ como base para produção de painéis aglomerados, o valor da massa específica média será no geral subestimado.

Analisando a massa específica básica para cada disco, representando as diversas alturas amostradas (Tabela 3), nota-se que, para o eucalipto, a massa específica básica decresce da base ao topo da árvore, enquanto para as outras espécies ocorre uma variação sem um padrão definido. Sendo assim, se não for usado todo o fuste comercial para produção de painéis aglomerados, sugere-se que o cálculo do valor da massa específica seja realizado para cada tora. Por outro lado, também não é possível utilizar o valor de massa específica dos discos do DAP como referencial para toda árvore, pois apresentam valores com diferença significativa em relação aos discos tomados ao longo do fuste, podendo subestimar ou superestimar a $\mathrm{Me}_{\mathrm{mp}}$.

Tabela 3. Massa específica básica da madeira $\left(\mathrm{Me}_{\mathrm{m}}\right)$ em relação à posição dos discos (altura).

Table 3. Density relative to the discs position (relative).

\begin{tabular}{lcccccc}
\hline & & \multicolumn{5}{c}{ Posição dos discos (altura em metros) } \\
\cline { 3 - 7 } Árvore & Espécie & $\mathbf{0 , 1 0}$ & $\mathbf{D A P}$ & $\mathbf{2 , 5 0}$ & $\mathbf{3 , 7 0}$ & $\mathbf{4 , 9 0}$ \\
\cline { 3 - 7 } & & $\begin{array}{c}\mathbf{M e}_{\mathbf{m}} \\
\mathbf{g} / \mathbf{c m}^{\mathbf{3}}\end{array}$ & $\begin{array}{c}\mathbf{M e}_{\mathbf{m}} \\
\mathbf{g} / \mathbf{c m}^{\mathbf{3}}\end{array}$ & $\begin{array}{c}\mathbf{M e}_{\mathbf{m}} \\
\mathbf{g} / \mathbf{c m}^{\mathbf{3}}\end{array}$ & $\begin{array}{c}\mathbf{M e}_{\mathbf{m}} \\
\mathbf{g} / \mathbf{c m}^{\mathbf{3}}\end{array}$ & $\begin{array}{c}\mathbf{M e}_{\mathbf{m}} \\
\mathbf{g} / \mathbf{c m}^{\mathbf{3}}\end{array}$ \\
\hline 1 & Bracatinga & 0,62 & 0,55 & 0,64 & 0,66 & 0,56 \\
2 & Bracatinga & 0,59 & 0,58 & 0,58 & 0,56 & 0,57 \\
3 & Pinus & 0,39 & 0,40 & 0,34 & 0,33 & 0,33 \\
4 & Pinus & 0,36 & 0,35 & 0,34 & 0,32 & 0,35 \\
5 & Uva-do-japão & 0,55 & 0,57 & 0,53 & 0,55 & 0,55 \\
6 & Uva-do-japão & 0,56 & 0,58 & 0,61 & 0,59 & 0,71 \\
7 & Eucalipto & 0,61 & 0,58 & 0,56 & 0,55 & 0,52 \\
\hline Média & & 0,52 & 0,52 & 0,51 & 0,51 & 0,51 \\
Desvio Padrão & & 0,108 & 0,096 & 0,124 & 0,131 & 0,131 \\
Coeficiente de Variação & & 0,206 & 0,185 & 0,242 & 0,257 & 0,256 \\
\hline
\end{tabular}




\section{Massa específica dos painéis}

Os valores médios encontrados para a massa específica básica ao $\mathrm{TUe}\left(\mathrm{Me}_{\mathrm{p}}\right)$ dos painéis e a taxa de compressão real, calculada pela razão entre $\mathrm{Me}_{\mathrm{p}}$ e a média de $\mathrm{Me}_{\mathrm{mp}}$ da mistura das madeiras utilizadas, estão apresentados na tabela 4. Os valores mínimos e máximos apresentados indicam que houve variações na massa específica dos painéis. Esse fato pode ser atribuído às condições experimentais de fabricação dos painéis no laboratório. $\mathrm{O}$ teste de Tukey indicou diferença estatisticamente significativa apenas entre o tratamento 6 e os demais tratamentos.

Tabela 4. Valores médios da massa específica básica ao teor de umidade de equilíbrio dos painéis $\left(\mathrm{Me}_{\mathrm{p}}\right)$ e taxa de compressão real.

Table 4. Average values of panel density $\left(\mathrm{Me}_{\mathrm{p}}\right)$ and real compression ratio.

\begin{tabular}{|c|c|c|c|c|c|c|}
\hline Trat. & Mistura das espécies / camada & Me & $\begin{array}{c}\text { Taxa de } \\
\text { Compressão real } \\
\end{array}$ & Mínimo & Máximo & $\begin{array}{l}\mathrm{CV} \\
(\%) \\
\end{array}$ \\
\hline 1 & $\begin{array}{c}50 \% \text { pinus e } 50 \% \text { bracatinga } \\
3 \text { camadas }\end{array}$ & $0,67 \mathrm{a}$ & 1,39 & 0,64 & 0,70 & 3,51 \\
\hline 2 & $\begin{array}{c}50 \% \text { pinus e } 50 \% \text { uva-do-japão } \\
3 \text { camadas }\end{array}$ & $0,66 \mathrm{a}$ & 1,42 & 0,65 & 0,68 & 1,81 \\
\hline 3 & $\begin{array}{l}50 \% \text { eucalipto e } 50 \% \text { bracatinga } \\
3 \text { camadas }\end{array}$ & $0,66 \mathrm{a}$ & 1,12 & 0,61 & 0,68 & 4,04 \\
\hline 4 & $\begin{array}{c}50 \% \text { eucalipto e } 50 \% \text { uva-do-japão } \\
3 \text { camadas }\end{array}$ & $0,68 \mathrm{a}$ & 1,19 & 0,66 & 0,70 & 2,66 \\
\hline 5 & $\begin{array}{c}100 \% \text { pinus industrial } \\
3 \text { camadas }\end{array}$ & 0,66 a & 1,65 & 0,63 & 0,70 & 4,17 \\
\hline 6 & $\begin{array}{l}100 \% \text { pinus laboratório } \\
3 \text { camadas }\end{array}$ & $0,60 \mathrm{~b}$ & 1,64 & 0,59 & 0,61 & 1,33 \\
\hline 7 & $100 \%$ pinus industrial homogêneo & $0,66 \mathrm{a}$ & 1,65 & 0,63 & 0,68 & 2,63 \\
\hline Média & & 0,65 & - & 0,59 & 0,70 & 4,52 \\
\hline
\end{tabular}

Médias seguidas por mesmas letras não diferem pelo teste de Tukey ao nível de $5 \%$ de probabilidade de erro. Para cálculo da taxa de compressão dos tratamentos 5 e 7 , atribuiu-se Me da madeira $=0,4 \mathrm{~g} / \mathrm{cm}^{3}$.

\section{Estabilidade dimensional}

Para a análise da estabilidade dimensional, foram consideradas as propriedades de inchamento em espessura, absorção d'água em peso e em volume. Essas variáveis foram determinadas após $2 \mathrm{~h}$ e $24 \mathrm{~h}$ de imersão em água, conforme preconiza a norma ASTM D1037-93 (ASTM, 2006).

Os resultados mostraram que os valores encontrados para as propriedades analisadas, quando comparados a outros resultados apresentados na literatura, foram inferiores ou semelhantes. Os valores mínimos e máximos observados nos tratamentos para as propriedades de inchamento em espessura e absorção d'água em peso deste estudo, bem como de estudos realizados por outros pesquisadores, são apresentados na tabela 5.

Tabela 5. Valores mínimos e máximos por tratamento das propriedades de inchamento em espessura e absorção d'água em peso de estudos com painéis aglomerados.

Table 5. Minimum and maximum values by treatment of mean thickness swelling and water absorption of particleboard panels studies.

\begin{tabular}{|c|c|c|c|c|}
\hline Referência bibliográfica & IE2(\%) & IE24(\%) & $\operatorname{AP2}(\%)$ & AP24(\%) \\
\hline Neste estudo & 2,28 a 6,34 & 5,78 a 11,11 & 1,6 a 23,1 & 10,4 a 35,7 \\
\hline Naumann et al. (2008) & 11,5 a 20.2 & 14,2 a 23,3 & 87,8 a 110,9 & 97,2 a 127,0 \\
\hline Iwakiri et al. (2010) & ------------- & 26,19 a 28,66 & -------- & 79,22 a 90,66 \\
\hline Bianche et al. (2012) & 13,13 a 44,49 & 33,02 a 53,41 & 17,41 a 84,45 & 57,62 a 107,38 \\
\hline Iwakiri et al. (2012) & 3,61 a 5,74 & 8,53 a 14,19 & 7,36 a 19,83 & 20,58 a 43,29 \\
\hline
\end{tabular}

\section{Inchamento em espessura}

Na tabela 6, são apresentados os valores médios do inchamento em espessura para os diferentes tratamentos. Tanto para o IE2 quanto para o IE24, os menores valores de inchamento em espessura foram obtidos para os tratamentos 2, 3, 4 e 5, cujos painéis foram produzidos, respectivamente, com misturas de pinus 
e uva-do-japão, eucalipto e bracatinga, eucalitpo e uva-do-japão e com partículas industriais de pinus. As médias obtidas para esses tratamentos foram estatisticamente inferiores em relação aos demais tratamentos.

Tabela 6. Valores médios de IE2 e IE24 para cada tratamento.

Table 6. Average values for IE2 and IE24 for each treatment.

\begin{tabular}{|c|c|c|c|c|}
\hline Trat. & Mistura das espécies / camada & $\operatorname{Me}\left(\mathrm{g} / \mathrm{cm}^{3}\right)$ & IE $2(\%)$ & IE $24(\%)$ \\
\hline 1 & $50 \%$ pinus e $50 \%$ bracatinga 3 camadas & 0,67 & $6,34 \mathrm{~d}$ & $11,11 \mathrm{c}$ \\
\hline 2 & $50 \%$ pinus e $50 \%$ uva-do-japão 3 camadas & 0,66 & $3,49 \mathrm{~b}$ & $7,57 \mathrm{~b}$ \\
\hline 3 & $50 \%$ eucalipto e $50 \%$ bracatinga 3 camadas & 0,66 & $3,31 \mathrm{ab}$ & $7,37 \mathrm{~b}$ \\
\hline 4 & $50 \%$ eucalipto e $50 \%$ uva-do-japão 3 camadas & 0,68 & $2,28 \mathrm{a}$ & $5,78 \mathrm{a}$ \\
\hline 5 & $100 \%$ pinus industrial 3 camadas & 0,66 & $2,84 \mathrm{ab}$ & $6,60 \mathrm{ab}$ \\
\hline 6 & $100 \%$ pinus laboratório 3 camadas & 0,60 & $5,18 \mathrm{c}$ & $11,08 \mathrm{c}$ \\
\hline 7 & $100 \%$ pinus industrial homogêneo & 0,66 & $5,32 \mathrm{~cd}$ & $11,09 \mathrm{c}$ \\
\hline Média & & 0,65 & 4,11 & 8,71 \\
\hline
\end{tabular}

Me: massa específica básica ao teor de umidade de equilíbrio; IE 2: inchamento em espessura após duas horas de imersão em água; IE 22: inchamento em espessura após 24 horas de imersão em água.

A análise geral dos resultados indica que os percentuais de inchamento em espessura obtidos nesta pesquisa encontram-se dentro dos valores exigidos pela norma DIN 68761(1)-1961(DIN, 1971), que estabelece o inchamento máximo de $6 \%$ e de $15 \%$, para IE2 e IE24, respectivamente, para painéis colados com ureia-formaldeído.

Comparando-se os resultados dos tratamentos 5,6 e 7, pode-se afirmar que as partículas geradas em processo industrial e o uso de painéis com três camadas contribuíram para a redução no inchamento em espessura, tanto para 2 quanto para 24 horas de imersão em água.

Verificou-se que os tratamentos que continham madeira de uva-do-japão e de eucalipto apresentaram menores valores médios de IE2 e IE24.

Wang e Winistorfer (2000), trabalhando com painéis OSB, observaram que os painéis produzidos com espécie de menor massa específica apresentaram maior inchamento em espessura quando comparados com espécies de maior massa específica. Neste trabalho, foi observada essa mesma tendência, uma vez que os tratamentos cujos painéis foram produzidos com partículas de pinus foram os que apresentaram maiores valores de inchamento em espessura.

Por outro lado, Iwakiri et al. (2010), num estudo com madeiras de Schizolobium amazonicum (paricá) e Cecropia hololeuca (embaúba), observaram que essas espécies de menor massa específica básica forneceram painéis que apresentaram menor inchamento em espessura que os painéis produzidos com Pinus taeda. Além disso, neste estudo verificou-se que, utilizando a madeira de uva-do-japão, obteve-se menor inchamento que quando se utilizou madeira de bracatinga, de menor massa específica básica. Assim, outros fatores inerentes às características anatômicas e físicas da madeira, além da massa específica básica, devem ter influência no inchamento em espessura.

Os resultados obtidos indicam que a melhor mistura para essa propriedade foi obtida para painéis produzidos com eucalipto e uva-do-japão, e a mistura que apresentou resultados inferiores foi a de pinus com bracatinga. Os painéis produzidos com misturas de pinus com uva-do-japão e eucalipto com bracatinga apresentaram valores intermediários.

\section{Absorção de água em peso (AP) e em volume (AV)}

A análise dos resultados da tabela 7 indicam que os maiores valores médios de absorção de água em peso e volume ( 2 e 24 horas) foram obtidos para o tratamento 1, cujos painéis foram produzidos com misturas de pinus e bracatinga. Para os demais tratamentos, no geral, não foram constatadas diferenças significativas entre as médias de absorção de água em peso e volume, tanto para 2 quanto para 24 horas de imersão em água. Portanto, não houve evidências claras dos efeitos da composição em camadas e do uso de partículas obtidas na indústria e no laboratório.

A análise geral dos resultados indica que as médias calculadas para AP24 e AV24 encontram-se na faixa de 10 a 50\% e de 5 a 50\%, respectivamente, conforme valores referenciados no Wood Handbook (1987).

\section{Análise de correlação entre variáveis}

A tabela 8 mostra a correlação de Pearson entre as variáveis de estabilidade dimensional, a massa específica e a proporção de cada espécie na mistura. Nessa análise, foram utilizados apenas os dados obtidos nos tratamentos em que os painéis foram produzidos com partículas de laboratório. 
Tabela 7. Média dos valores de absorção de água (AP2, AP24, AV2 e AV24) de todos os tratamentos. Table 7. Mean values of water absorption (AP2, AP24, AV24 and AV2) of all treatments.

\begin{tabular}{|c|c|c|c|c|c|c|}
\hline Trat. & Mistura das espécies / camada & $\mathrm{Me}\left(\mathrm{g} / \mathrm{cm}^{3}\right)$ & AP2 (\%) & AP24 (\%) & AV2 (\%) & AV24 (\%) \\
\hline 1 & $\begin{array}{l}50 \% \text { pinus e } 50 \% \text { bracatinga } \\
3 \text { camadas }\end{array}$ & 0,67 & $23,1 \mathrm{~b}$ & $35,7 \mathrm{~d}$ & $15,5 \mathrm{c}$ & $23,9 \mathrm{~d}$ \\
\hline 2 & $\begin{array}{l}50 \% \text { pinus e } 50 \% \text { uva-do-japão } \\
3 \text { camadas }\end{array}$ & 0,66 & $3,6 \mathrm{a}$ & $13,3 \mathrm{abc}$ & $2,4 \mathrm{ab}$ & $8,8 \mathrm{~b}$ \\
\hline 3 & $\begin{array}{l}50 \% \text { eucalipto e } 50 \% \text { bracatinga } \\
3 \text { camadas }\end{array}$ & 0,66 & $2,8 \mathrm{a}$ & $12,7 \mathrm{ab}$ & $1,8 \mathrm{ab}$ & $8,2 \mathrm{ab}$ \\
\hline 4 & $\begin{array}{l}50 \% \text { eucalipto e } 50 \% \text { uva-do-japão } \\
3 \text { camadas }\end{array}$ & 0,68 & $1,6 \mathrm{a}$ & $10,4 \mathrm{a}$ & $0,6 \mathrm{a}$ & $6,5 \mathrm{a}$ \\
\hline 5 & $\begin{array}{c}100 \% \text { pinus industrial } \\
3 \text { camadas }\end{array}$ & 0,66 & $3,5 \mathrm{a}$ & $12,4 \mathrm{ab}$ & $2,9 \mathrm{~b}$ & $8,8 \mathrm{ab}$ \\
\hline 6 & $\begin{array}{l}100 \% \text { pinus laboratório } \\
3 \text { camadas }\end{array}$ & 0,60 & $4,0 \mathrm{a}$ & $16,8 \mathrm{c}$ & $2,4 \mathrm{ab}$ & $10,1 \mathrm{bc}$ \\
\hline 7 & $100 \%$ pinus industrial homogêneo & 0,66 & $2,4 \mathrm{a}$ & $15,7 \mathrm{bc}$ & $2,5 \mathrm{ab}$ & $11,3 \mathrm{c}$ \\
\hline Média & & 0,65 & 5,9 & 16,7 & 4,0 & 11,1 \\
\hline
\end{tabular}

Pode-se observar que houve correlação significativa ao nível de 5\% de probabilidade de erro entre as variáveis de estabilidade dimensional e diferentes proporções de misturas de eucalipto, bracatinga e uva-do-japão.

Tabela 8. Correlação de Pearson entre as variáveis do processo de manufatura e as propriedades de estabilidade dimensional dos painéis.

Table 8. Pearson's correlation between the manufacturing variables and dimensional stability of the panels.

\begin{tabular}{lcccccc}
\hline & IE2 & IE24 & AP2 & AP24 & AV2 & AV24 \\
\hline P (\%) & 0,288 & $0,527^{*}$ & $-0,009$ & 0,109 & 0,047 & 0,134 \\
E (\%) & $-0,436^{*}$ & $-0,569^{*}$ & $-0,319^{*}$ & $-0,399^{*}$ & $-0,364^{*}$ & $-0,425^{*}$ \\
B (\%) & 0,304 & 0,139 & $0,623^{*}$ & $0,574^{*}$ & $0,607^{*}$ & $0,573^{*}$ \\
U (\%) & $-0,399^{*}$ & $-0,542^{*}$ & $-0,287$ & $-0,377^{*}$ & $-0,329^{*}$ & $-0,395^{*}$ \\
Me & $-0,159$ & $-0,295$ & 0,085 & $-0,037$ & 0,135 & 0,067 \\
TC & $0,329 *$ & $0,530^{*}$ & $-0,006$ & 0,100 & 0,056 & 0,137 \\
IE2 & 1 & $0,873^{*}$ & $0,628^{*}$ & $0,749^{*}$ & $0,631^{*}$ & $0,742^{*}$ \\
IE24 & & 1 & $0,440^{*}$ & $0,593^{*}$ & $0,475^{*}$ & $0,606^{*}$ \\
AP2 & & & 1 & $0,970^{*}$ & $0,982^{*}$ & $0,962^{*}$ \\
AP24 & & & & 1 & $0,948^{*}$ & $0,981^{*}$ \\
AV2 & & & & & 1 & $0,976^{*}$ \\
\hline
\end{tabular}

P: pinus; E: eucalipto; B: bracatinga; U: uva-do-japão; Me: massa específica dos corpos de prova; TC: taxa de compressão; IE2: inchamento em espessura após 2 horas de imersão em água; IE24: inchamento em espessura após 24 horas de imersão em água; AP2: absorção d'água em peso após 2 horas de imersão em água; AP24: absorção d'água em peso após 24 horas de imersão em água; AV2: absorção d'água em volume após 2 horas de imersão em água; AV24: absorção d'água em volume após 24 horas de imersão em água. *: significativo ao nível de 5\% de probabilidade de erro.

Foram constatadas correlações significativas para o inchamento em espessura após 2 horas de imersão (IE2) e após 24 horas de imersão (IE24) com todas as outras variáveis de estabilidade dimensional e com as proporções de madeira de eucalipto e de uva do japão. Para IE24, foi também observada correlação significativa com a proporção de pinus.

Também houve correlações significativas entre a absorção de água em peso e em volume, demonstrando que há comportamento similar entre as duas propriedades avaliadas. Quanto à correlação com as proporções de madeira nas misturas de espécies, a absorção de água segue a mesma tendência do inchamento em espessura, em que as madeiras de eucalipto e de uva-do-japão influenciaram positivamente. Por outro lado, a proporção de madeira de pinus não apresentou correlação significativa 
com a absorção d'água, e a proporção de madeira de bracatinga apresentou correlação positiva, ou seja, contribuiu para aumento da absorção d'água.

Por outro lado, não foi observada correlação significativa para a relação entre massa específica básica ao TUe do painel e seu inchamento, pois a massa específica foi fixada em $0,65 \mathrm{~g} / \mathrm{cm}^{3}$ e não houve diferença significativa entre os tratamentos, exceto o 6. Por outro lado, verificou-se uma correlação significativa e positiva entre a taxa de compressão (TC) e o inchamento em espessura (IE2 e IE24). Esse fato pode ser constatado nos tratamentos 1 e 6 , nos quais o inchamento em espessura foi maior para os painéis com maior taxa de compressão. Entretanto, essa tendência não foi observada para o tratamento 2, o que pode ser resultante de uma interação negativa entre madeiras de pinus e bracatinga.

\section{CONCLUSÕES}

- Verificou-se que a média ponderada da massa específica básica das árvores amostradas está acima dos padrões recomendados pela literatura para a produção de painéis aglomerados, com exceção do pinus, mostrando que o uso das madeiras de eucalipto, bracatinga e uva-do-japão em misturas com madeiras mais leves é apropriado.

- Houve diferenças entre os valores de massa específica média aritmética $\left(\mathrm{Me}_{\mathrm{ma}}\right)$ e de massa específica média ponderada $\left(\mathrm{Me}_{\mathrm{mp}}\right)$ para todas as árvores utilizadas, indicando que o uso da $\mathrm{Me}_{\mathrm{ma}}$ não é adequado para cálculo de quantidade de materiais para produção de painéis aglomerados.

- A adição de madeira de eucalipto e de uva-do-japão nos painéis influenciou de forma positiva no inchamento em espessura, com a redução no inchamento em espessura dos painéis. A mistura de madeira de bracatinga apresentou correlação diretamente proporcional com a absorção de água, enquanto as madeiras de eucalipto e de uva-do-japão apresentaram relação inversamente proporcional. A mistura de madeira de pinus não apresentou correlação significativa com a absorção d'água, no entanto sua mistura com bracatinga mostrou uma interação negativa, que necessita de maiores estudos.

- De forma geral, os painéis produzidos com 50\% de madeira de eucalipto e 50\% de madeira de uvado-japão foram os que apresentaram melhor estabilidade dimensional, ao contrário dos painéis produzidos com $50 \%$ de madeira de pinus e $50 \%$ de madeira de bracatinga.

- Os painéis de três camadas, produzidos com partículas de pinus obtidas da linha de produção industrial apresentaram menor inchamento em espessura em relação aos painéis homogêneos e aos painéis produzidos com partículas obtidas no laboratório.

\section{REFERÊNCIAS}

ASSOCIAÇÃO BRASILEIRA DA INDÚSTRIA DE PAINÉIS DE MADEIRA (ABIPA). Números. Disponível em: <http://www.abipa.org.br/numeros.php>. Acesso em: 14/10/2010.

ASTM. Standard test methods for evaluating properties of wood-base fiber and particle panel materials. D1037 - 93. Philadelphia, PA. 2006.

BIANCHE, J. J.; CARNEIRO, A. C. O.; VIDAL, B. R.; PEREIRA, F. A.; SANTOS, R. C.; SORATTO, D. N. Propriedades de painéis aglomerados fabricados com partículas de eucalipto (Eucalyptus urophylla), paricá (Schizolobium amazonicum) e vassoura (Sida spp.). Cerne, Lavras, v. 18, n. 4, p. 623 630, 2012.

CABRAL, C. P.; VITAL, B. R.; LUCIA, R. M. D.; PIMENTA, A. S. Propriedades de chapas de aglomerado confeccionadas com misturas de partículas de Eucalyptus spp. e Pinus elliottii. Revista Árvore, v. 31, n. 5, p. 897 - 905, 2007.

CARVALHO, P. E. R. Ecologia, silvicultura e usos da uva-do-japão (Hovenia Dulcis Thunberg). EMBRAPA, Circular técnica nº 23, Colombo-PR, 1994.

DIN. GERMAN STANDARDS COMMITTEE: Deutschem Normanausschuss. Specifications for particleboard. DIN 68761(1) - 1961 (3). Holz, 1971. 
HASELEIN, C. R.; VITAL, B. R.; DELLALUCIA, R. M. Fabricação de chapas de aglomerado com madeiras de eucalipto (Eucalyptus grandis W. Hill ex. Maiden) e embaúba (Cecropia sp.). Revista Árvore, v. 13, n. 1, p. 67 - 84, 1989.

HILLIG, É.; HASELEIN, C. R.; SANTINI, E. J. Propriedades mecânicas de chapas aglomeradas estruturais fabricadas com madeiras de pinus, eucalipto e acácia-negra. Revista Ciência Florestal, Santa Maria, RS, v. 12, n. 1, p. 59 - 70, 2002.

HIZIROGLU, S.; JARUSOMBUTI, S.; FUEANGVIVAT, V.; BAUCHONGKOL, P.; SOONTONBURA, W.; DARAPAK, T. Properties of bamboo - rice straw - eucalyptus composite panels. Forest Products Journal, v. 55, n. 12, p. 221 - 225, 2005.

IWAKIRI, S. Painéis de madeira reconstituída. Curitiba: FUPEF, 2005. 247 p.

IWAKIRI, S.; ZELLER, F.; PINTO, J. A.; RAMIREZ, M. G. L.; SOUZA, M. M.; SEIXAS, R. Avaliação do potencial de utilização da madeira de Schizolobium amazonicum "Paricá" e Cecropia hololeuca "Embaúba" para produção de painéis aglomerados. Acta Amazonica. v. 40, n. 2, p. 303 - 308, 2010.

IWAKIRI, S.; MATOS, J. L. M.; TRIANOSKI, R.; PRATA, J. G. Produção de painéis aglomerados homogêneos e multicamadas de Melia azedarach (cinamomo) e Pinus taeda com diferentes teores de resina. Cerne, Lavras, v. 18, n. 3, p. 465 - 470, 2012.

LORENZI, H. Árvores brasileiras, vol.1, 4 ed., Nova Odessa, SP: Instituto Plantarum, 2002.

MALONEY, T. M. Modern particleboard \& dry-process fiberboard. San Francisco: Miller Freeman, 1993. $681 \mathrm{p}$.

NAUMANN, R. B.; VITAL, B. R.; CARNEIRO, A. C. O.; DELlA LUCIA, R. M.; SILVA, J. C.; CARVALHO, A. M. M. L.; COLLI, A. Propriedades de chapas fabricadas com partículas de madeira de Eucalyptus urophylla S. T. Blake e Schizolobium amazonicum Herb. Revista Árvore, Viçosa, v. 32, n. 6, p. 1143 - 1150, 2008.

VITAL, B. R. Métodos de determinação da densidade da madeira. Boletim técnico SIF, Viçosa, n. 1, p. 1 - 21, 1984.

WANG, S.; WINISTORFER, P. M. The effect of species and species distribution on the layer characteristics of OSB. Forest Products Journal. v. 50, n. 4, p. 37 - 48. 2000.

WOOD HANDBOOK. Wood as an Engineering Material. Agric. Handb. 72. Washington, DC: U.S. Department of Agriculture; rev. 1987. 